\title{
Revision rates for metal on metal hip joints are double that of other materials
}

\author{
Deborah Cohen
}

BMJ

Performance of the controversial metal on metal hip prostheses "continues to create cause for concern," says the latest annual report from the National Joint Registry of England and Wales. Revision rates-how likely it is that a patient will need an operation to replace a prosthesis-for hip replacements are by far the highest overall for metal on metal (so called because the head and the lining of the cup are both made of metal) hip devices, the report says.

Hip replacement falls into two main categories, and the report shows that revision rates differ with the type of procedure used and the patient's sex. For resurfacing, the latest revision rate is $11.8 \%$ at seven years on average, and for all metal on metal total hip replacement it is $13.6 \%$, although failure rates vary with the brand used. Over the same time, however, revision rates for using hip implants made of other materials for hip replacements were between $3.3 \%$ and $4.9 \%$.

The report says that the highest failure rates involved the now recalled articular surface replacement (ASR) total hip implant made by DePuy. Of those patients who received the device six years ago $29 \%$ have since had it replaced.
Despite reports from Australia and data from surgeons over several years indicating that the implant was causing problems, it was figures from the National Joint Registry in 2010 that led to the worldwide recall of the ASR (BMJ 2011;342:d2905, doi:10.1136/bmj.d2905).

And this year's report suggests that this recall—along with growing concern among orthopaedic specialists about the revision rates of metal on metal hips-has affected surgeons' choice over what to use. The report shows that metal on metal hips were used in only $5 \%$ of procedures recorded on the register since 2010, down from 15\% in 2006 and 2007.

The National Joint Registry's 8th annual report is at http://bit.ly/mVNDH5. The Medicines and Healthcare Products Regulatory Agency's report of the expert advisory group looking at soft tissue reactions associated with metal on metal hip replacements is at http://bit.ly/r8uDhz.

Cite this as: BMJ 2011;343:d5977

๑ BMJ Publishing Group Ltd 2011 